Bergersen, F. J. (1958). J. gen. Microbiol. 19, 312-323

\title{
The Bacterial Component of Soybean Root Nodules; Changes in Respiratory Activity, Gell Dry Weight and Nucleic Acid Content with Increasing Nodule Age
}

\author{
By F. J. BERGERSEN \\ Division of Plant Industry, C.S.I.R.O., Canberra, Australia
}

\begin{abstract}
SUMMARY: During the 6- to 7-week active life of soybean root nodules produced by a single strain of Rhizobium japonicum, the respiratory activity of the bacteria isolated from the nodules changed according to a definite pattern: a depression occurred 2 weeks after nodules first appeared, followed by a rise, and with a further sharp rise 1 week before nodule breakdown. The initial depression coincided with the onset of the bacteroid condition and the beginning of nitrogen fixation. The limits within which respiration varied depended on host-plant growth. The nitrogenfixation rate remained constant from 2-3 weeks after nodule appearance until a few days before nodule decay began. The bacteroids isolated from the nodule did not oxidize substrates of the tricarboxylic acid cycle to completion, but the number of mole $\mathrm{O}_{2}$ consumed/mole substrate did not change during nodule life, and were similar to values obtained for cultures of the free living bacteria. Changes in bacteroid dry weight and nucleic acid content were observed; these were within the limits of dry weight and nucleic acid content of the same bacterial strain grown in liquid culture. The ratio acid soluble nucleotides: nucleic acid for bacteroids was between 0.12 and 0.13 during nitrogen fixation; these values are characteristic of bacteria of the same strain from the mid-logarithmic phase of growth in culture in spite of the fact that bacteroids are non-proliferating cells.
\end{abstract}

Allen \& Allen (1950), Wilson \& Burris (1953) and Nutman (1956) have reviewed much of the literature relating to the fixation of atmospheric nitrogen by legume root nodules, and the author (Bergersen, 1957) has summarized the known structural abnormalities of nodules which interfere with their nitrogen-fixing functions. It was shown that all of these abnormalities represented failures in the development of the intimate association between hostplant cell and the symbiotically adapted Rhizobium-the so-called 'bacteroids'. The essential role of these bacteroids in the nitrogen fixation accomplished by legume root nodules has been inferred from the results of several workers. For example, Chen \& Thornton (1940) showed that differences in the volume and duration of the 'bacterial tissue' accounted for differences in nitrogen fixation in clover, pea and soybean nodules. In contrast, there is no authenticated evidence for nitrogen fixation by Rhizobium spp. in culture. It is therefore surprising that there have been relatively few studies of nodule bacteria isolated from nitrogen-fixing nodules.

For the purposes of these studies the term 'bacteroid' will be used irrespective of external morphology for the non-proliferating intracellular forms of Rhizobium found in the bacterial tissue of root nodules, in order to distinguish the somewhat unique functions and properties of these forms from those of the 
free-living or cultured forms of the bacteria. The following are some of the reports which deal with the properties of bacteroids. Almon (1933) demonstrated the inability of bacteroids from nodules of peas, clover and alfalfa to grow on media which supported growth of the original cultures. Burris \& Wilson (1939) and Thorne \& Burris (1940) reported studies of the respiration of bacteroids as compared with that of cultures and concluded that the respiration was basically similar in both types of cells. Wilson \& Burris (1943) failed to demonstrate hydrogenase in suspensions of bacteroids. Rautanen \& Saubert (1955) studied the composition of various soybean and cowpea nodule fractions and showed different distributions of iron, phosphorus, nitrogen and nucleic acids when the bacteroid fraction was compared with cultured bacteria. Cheniae \& Evans (1956) found that soybean bacteroids possessed nitrate reductase, whereas the bacteria grown in culture did not unless they were grown in the presence of nitrate. The author (Bergersen, 1955) demonstrated nuclear and cytoplasmic changes during bacteroid formation in subterranean clover nodules.

There is little information in the literature of symbiotic nitrogen fixation about the functions of bacteroids during nodule life; nor have the essential differences between bacteroids and Rhizobium organisms in culture been defined, apart from the work quoted above. The present paper reports observations of an experimental system in which bacteroid activity as measured by their respiration in air was examined at intervals during the development and active life of soybean root nodules. At the same time the nitrogen increments of the plants were determined in order to find whether there was any relationship between bacteroid respiratory changes and nitrogen fixation. The non-proliferating nature of the mature bacteroids suggested an examination of their nucleic acid content. The same bacteroid suspensions as used for the respiratory measurements were therefore examined for this purpose. The results from all of these observations were then compared with similar observations made at intervals during growth of the same strain of Rhizobium in culture.

\section{METHODS}

Plant material. Lincoln strain soybeans (Glycine max Merr.) were grown in sterilized soil or in a mixture of sand and vermiculite $(1: 1, v / v)+$ nitrogenfree nutrient salts solution (McKnight, 1949), in an air-conditioned glasshouse. The seeds were sterilized with $\mathrm{HgCl}_{2}$ solution $(0.001 \%, \mathrm{w} / \mathrm{v})$ and heavily inoculated with the nodule bacteria at sowing and again a few days after the opening of the cotyledons. The plants grown in soil were watered with boiled tap water when necessary and those grown in sand + vermiculite were watered, to maintain the volume of solution originally added, alternately with sterile distilled water or nutrient solution every 2 days. The first experiment was conducted during the summer when the plants grew to 4-5 ft. before flowering; under these conditions successive crops of nodules were produced at about 14-day intervals as the root system enlarged. The time of appearance of the first nodules was recorded and only the oldest sets of nodules were used; these 
were easily distinguished by their position and size. The other experiments were conducted during the winter when flowering began 2-3 weeks after germination, and plants stopped making leaf growth once seeds were forming. Under these conditions only one set of nodules was produced on each plant, 15 nodules by the end of the first week from onset of nodulation and a further 8 during the next 2 weeks, after which nodule number remained constant (Fig. 1). Samples of nodules from each harvest were fixed in Flemming's solution, embedded in paraffin wax and microtome sections prepared for examination of detailed nodule development.

Organism. Rhizobium japonicum strain CC711 was maintained on yeastextract mannitol agar. For the examination of bacteria grown in vitro, $300 \mathrm{ml}$. conical flasks containing $100 \mathrm{ml}$. yeast-extract mannitol broth were inoculated and agitated on a rotary shaker at $20^{\circ}$, a temperature corresponding to the mean soil temperature for the plants grown in the glasshouse. Growth was followed turbidimetrically with an EEL photoelectric nephelometer. Suspensions of rhizobia were concentrated and washed in five changes of buffer.

Bacteroid suspensions. Nodules were harvested at weekly intervals, beginning 1 week after the appearance of the first nodules, and dropped into cold $\mathrm{M} / \mathbf{1 5}$ phosphate buffer ( $\mathrm{pH} \mathbf{7 \cdot 0}$ ). They were rinsed clean in buffer and then crushed (not ground) with a cold pestle and mortar. The crushed nodules were filtered under slight vacuum through Whatman no. 4 filter-paper to remove nodule debris. The pink suspension was then centrifuged at $300 \mathrm{~g}$ for $4 \mathrm{~min}$. in an angle centrifuge to remove coarse starch grains and then at $4500 \mathrm{~g}$ for 6-8 min. to sediment the bacteroids. The resulting pink pellet was then washed in four changes of buffer after which $90-96 \%$ of the microscopically visible particles were bacteroids and most of the remainder small starch grains. The concentration of the suspension was then adjusted by turbidity to approximately $10^{10}$ bacteroids $/ \mathrm{ml}$.

Bacterial counts. The numbers of bacteria/ml. suspension were estimated in two ways. (a) $1 \mathrm{ml}$. of suspension was diluted to $100 \mathrm{ml} ., 4$ drops of $1 \%(\mathrm{w} / \mathrm{v})$ Victoria blue $\mathbf{4 R}$ added to stain the bacteria, and this suspension counted in a haemacytometer chamber. (b) $1 \mathrm{ml}$. of suspension was mixed with $1 \mathrm{ml}$. of a suspension containing an accurately known concentration of formalinized sheep erythrocytes; drops of the mixture were then spread evenly over standard areas of four microscope slides, dried by heat and stained with carbol-fuchsin. The mean ratio of bacteria to erythrocytes in the mixture was determined and from this and the erythrocyte concentration the bacterial numbers were calculated.

Dry-weight determinations. Plant materials were dried at $120^{\circ}$ for $8 \mathrm{hr}$. Bacterial suspensions were dried to constant weight at $100^{\circ}$.

Nitrogen determinations. Dried plant material from the nitrogen-free pot cultures was ground by hand and the quantity of nitrogen/plant determined by the Kjeldahl method. From weekly nitrogen values rates of nitrogen fixation were obtained. Total bacterial-nitrogen was determined according to Umbreit, Burris \& Stauffer (1945). 
Measurement of oxygen uptake. This was done in a Warburg apparatus at $30^{\circ}$ using a shaking rate of 150 oscillations/min. with air as the gas phase. Vessels contained $1.7 \mathrm{ml}$. of $\mathrm{M} / 15$ substrates and $1 \mathrm{ml}$. of cell suspension in M/15 buffer with $0.2 \mathrm{ml} .20 \%(\mathrm{w} / \mathrm{v}) \mathrm{KOH}$ in the centre well. Where both respiratory rate and mole $\mathrm{O}_{2}$ used/mole substrate were determined, the vessels contained $0.5 \mathrm{ml} .0 .005 \mathrm{M}$ substrate in the sidearms, with $1 \mathrm{ml}$. of cells in buffer $+1 \mathrm{ml}$. of buffer in the flask. The first experiments used the Na salts of succinic, fumaric, malic, acetic, citric and pyruvic acids as substrates. In later experiments succinate and citrate were used as being typical of the two types of response being observed. In the control flasks buffer replaced the M/15 substrate and water the $0.005 \mathrm{M}$ substrate. For the purposes of this study oxygen uptakes were expressed in terms of $\mu \mathrm{l}$. oxygen $/ 10^{10}$ cells $/ \mathrm{hr}$., $q_{\mathrm{o}_{2}}$ (cell) since it was desired to compare cellular activities rather than activity/unit cell constituent (total $\mathrm{N}$ or dry weight).

Nucleic acid determinations. The method was based on procedures used by Mitchell \& Moyle (1951) and Gale \& Folkes (1953). Ten ml. of washed bacterial suspension were extracted at $0^{\circ}$ with $2 \mathrm{ml}$. of $30 \%(\mathrm{w} / \mathrm{v})$ trichloroacetic acid for $30 \mathrm{~min}$. The bacteria were then sedimented at about $600 \mathrm{~g}$ at $4^{\circ}$ and the supernatant fluid containing acid-soluble nucleotides (NT), was collected. The extracted organisms were then washed twice with distilled water and extracted three times for $10 \mathrm{~min}$. at $90^{\circ}$ with $2 \mathrm{ml} .5 \%(\mathrm{w} / \mathrm{v})$ trichloroacetic acid. These extracts containing nucleic acids (NA) were pooled and made to $10 \mathrm{ml}$. with distilled water. Further extraction did not increase the NA yield. The NT and NA fractions were slightly opalescent, probably due to traces of lipid in the extracts. They were examined in a Hilger 'Uvispek' spectrophotometer, optical density being measured at $350 \mathrm{~m} \mu$ to give, by extrapolation, the background density due to light scattering at the nucleic acid absorption peaks, which for the NT was $260 \mathrm{~m} \mu$ and for the NA $268 \mathrm{~m} \mu$. An extinction coefficient of 220 (for $1 \%$ nucleic acid in a $1 \mathrm{~cm}$. light path absorption cell) was used for the NT fraction and 280 for the NA (Malmgren \& Heden, 1947; Gale \& Folkes, 1953). All spectrophotometric measurements were made against blanks containing the same reagents as the extracts and all estimations were done in triplicate.

\section{RESULTS}

\section{Nodule development}

The structural development of the nodules used in these experiments merits emphasis. Microscopic examination of samples of nodules from each harvest revealed two important features.

(a) The bacterial tissue in individual nodules was uniform (in contrast to that of elongating nodules from other types of legumes). This was because nodule development proceeded in well-defined stages: first a small locus of infected cells and the surrounding root cortex cells multiplied to give a ball of small host cells each containing a few bacterial rods and surrounded by the developing cortex, vascular system and endodermis of the nodule. Next the bacteria multiplied greatly and the host cells containing them enlarged; this 
was complete in most nodules by the second harvest, 2 weeks from the appearance of the first nodules. The central cells of the nodules and the bacteria within them then increased in size but not in number until 4 weeks from nodule appearance; the nodule structure then remained static until 6-7 weeks when the nodule contents began to degenerate. Thus the first 2 weeks of nodule development was the total period of bacterial proliferation, until decay began. These microscopic findings agree with the nodule weight data of Fig. 1 .

(b) The nodule samples were themselves fairly uniform due to the selection of nodules of similar age or due to the production of only one set of nodules on each plant.

From this information it seems logical to assume that the activities and constitution of the pooled bacterial suspensions were representative of the individual bacteria within any nodule cell at the particular stage of development at which the nodules were harvested, except in the case of harvest 2 when the suspension largely consisted of bacteroids, but with a few proliferating bacteria from the nodules in which cell division was still occurring.

\section{Nitrogen fixation}

From the total plant nitrogen of nodulated plants grown in nitrogen-free culture, under conditions where only one set of nodules was produced, it was found that plant-total nitrogen increased at a constant rate from about $2 \frac{1}{2}$ to

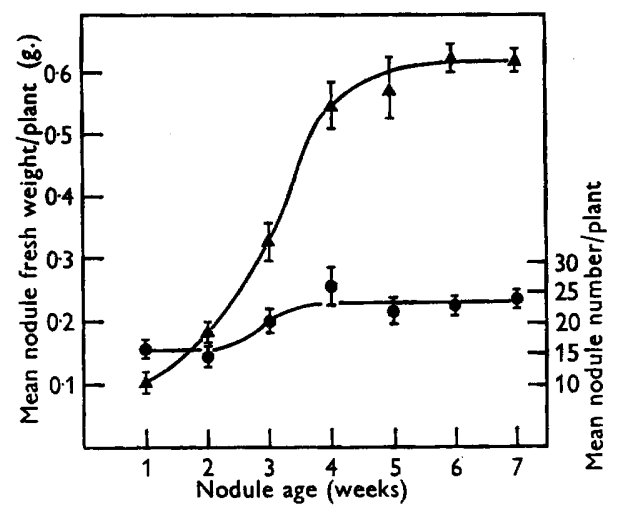

Fig. 1

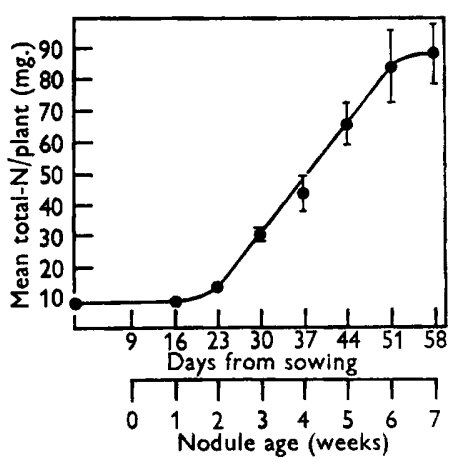

Fig. 2

Fig. 1. Nodule growth of plants growing in $\mathbf{N}$-free culture in winter. The vertical lines indicate the magnitude of the standard errors of the means. - - mean nodulc number/plant; $\boldsymbol{\Delta}-\boldsymbol{\Delta}=$ mean nodule fresh weight/plant.

Fig. 2. Total nitrogen of nodulated plants grown in $\mathrm{N}$-free culture in winter. The vertical lines indicate the magnitude of the standard error of the means.

6 weeks after the beginning of nodulation. Nodule decay had begun by 7 weeks and fixation had ceased (Fig. 2). From germination the foliage of the plants became increasingly yellow until 15 days after the beginning of nodulation, when the plants became bright green overnight. 


\section{Bacteroid respiration}

The first experiments with bacteria from nodules on summer-grown plants revealed that the values of $q_{\mathrm{o}_{\mathrm{a}}}$ varied with the age of the nodules. This variation was greater with succinate and fumarate than with the other substrates with which respiration closely followed changes in endogenous activity (Fig. 3a). There was a sharp decrease in respiration with all substrates 1 week after the onset of nodulation, followed by a rise, then a steady period followed by a sudden and very significant rise when the nodules were about 7 weeks old. This general pattern was again obtained with nodules grown during the winter in nitrogen-free culture or in soil. However, the values of respiration within which the above variations occurred differed between nodules from summer and winter-grown plants and between plants grown in nitrogen-free culture and in soil (Fig. $3 a-c$ ).

None of the tricarboxylic acid cycle intermediates tested as substrates with whole bacteroids caused the theoretical oxygen uptake for complete oxidation (Table 1a). However, the molar uptakes of oxygen by the bacteroids differed

Table 1. Incomplete oxidation of tricarboxylic acid cycle intermediates by bacteria from culture and bacteroids from nodules

Warburg vessels contained bacterial suspensions in $\mathrm{M} / 15$ phosphate buffer with $0.5 \mathrm{ml}$. of the $0.005 \mathrm{M}$ substrates as $\mathrm{Na}$ salts in the sidearms. All measurements were made at $30^{\circ}$ with a shaking rate of 150 oscillations $/ \mathrm{min} . \mathrm{CO}_{2}$ was absorbed by $0.2 \mathrm{ml} .20 \%(\mathrm{w} / \mathrm{v}) \mathrm{KOH}$ on a filter-paper wick in the centre well. The substrates were added by tipping after 20 min. equilibration followed by measurement of endogenous activity for half an hour. $\mathrm{O}_{2}$ uptake/ mole substrate was calculated from differences between endogenous uptake and that due to added substrate when the rates of uptake in the flasks with added substrate returned to the endogenous rate.

(a)

$\begin{array}{lccc}\text { Bacteria from } \\ \begin{array}{c}\text { 10-day-old } \\ \text { culture }\end{array} & \begin{array}{c}\text { Bacteroids from } \\ \text { 5-week-old } \\ \text { nodules }\end{array} & \begin{array}{c}\text { Theoretical to } \\ \text { completion }\end{array} \\ \text { Substrate } & 0.8 & 1.0^{*} & 3.5 \\ \text { Succinate } & 0.4 & 1 \cdot 0 & \mathbf{3 . 0} \\ \text { Fumarate } & 0.3 & 0.3 & 3.0 \\ \text { Malate } & 0.0 & 0.3 & \mathbf{2 . 5} \\ \text { Pyruvate } & 0.5 & 0.8 & 2 \cdot 0 \\ \text { Acetate } & 0.8 & 1.0 & 4.5 \\ \text { Citrate } & & & \mathrm{O}_{2} / \text { mole substrate) }\end{array}$

(b)

$\begin{array}{cc}\begin{array}{c}\text { Bacteroids from } \\ \text { nodules aged } \\ \text { (weeks) }\end{array} & \begin{array}{c}\text { Oxygen uptake- } \\ \text { mole } \mathrm{O}_{2} / \text { mole } \\ \text { succinate }\end{array} \\ 1 & 1 \cdot 0 \\ 2 & 1 \cdot 1 \\ 3 & 0 \cdot 9 \\ 4 & 0 \cdot 9 \\ 5 & 1 \cdot 1^{*} \\ 6 & 1 \cdot 2 \\ 7 & 1 \cdot 1\end{array}$

* Different experiments. 


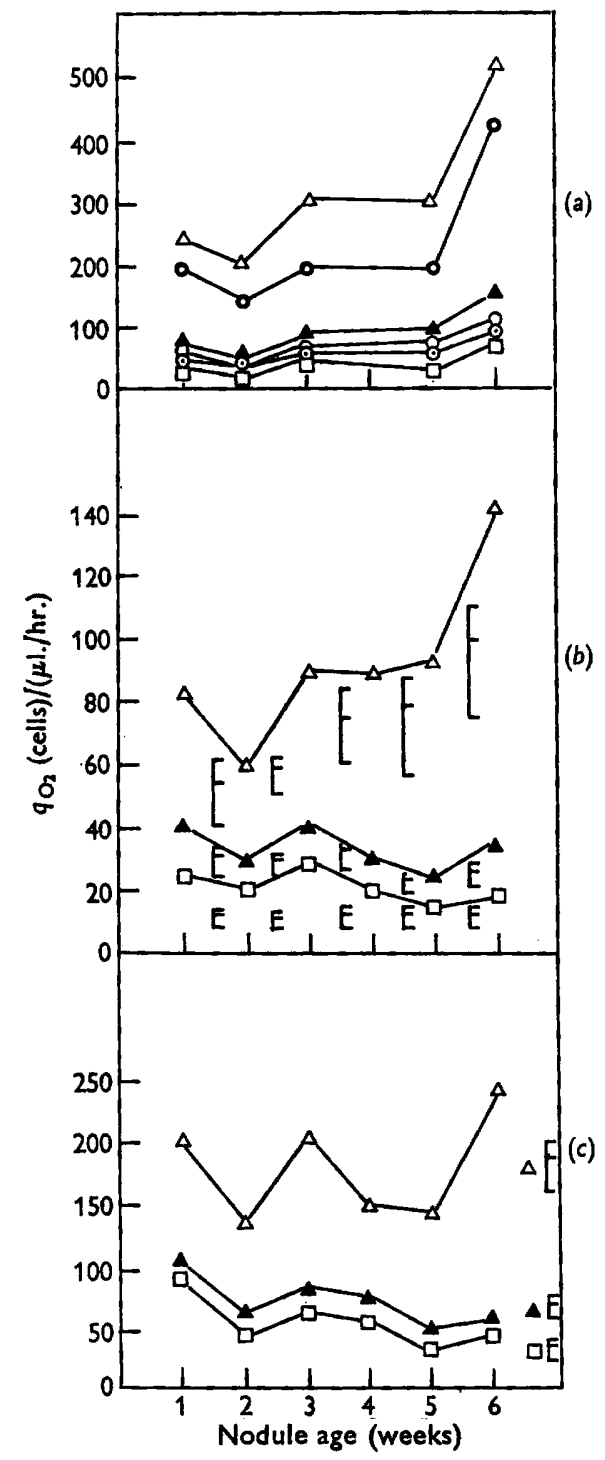

Fig. 3

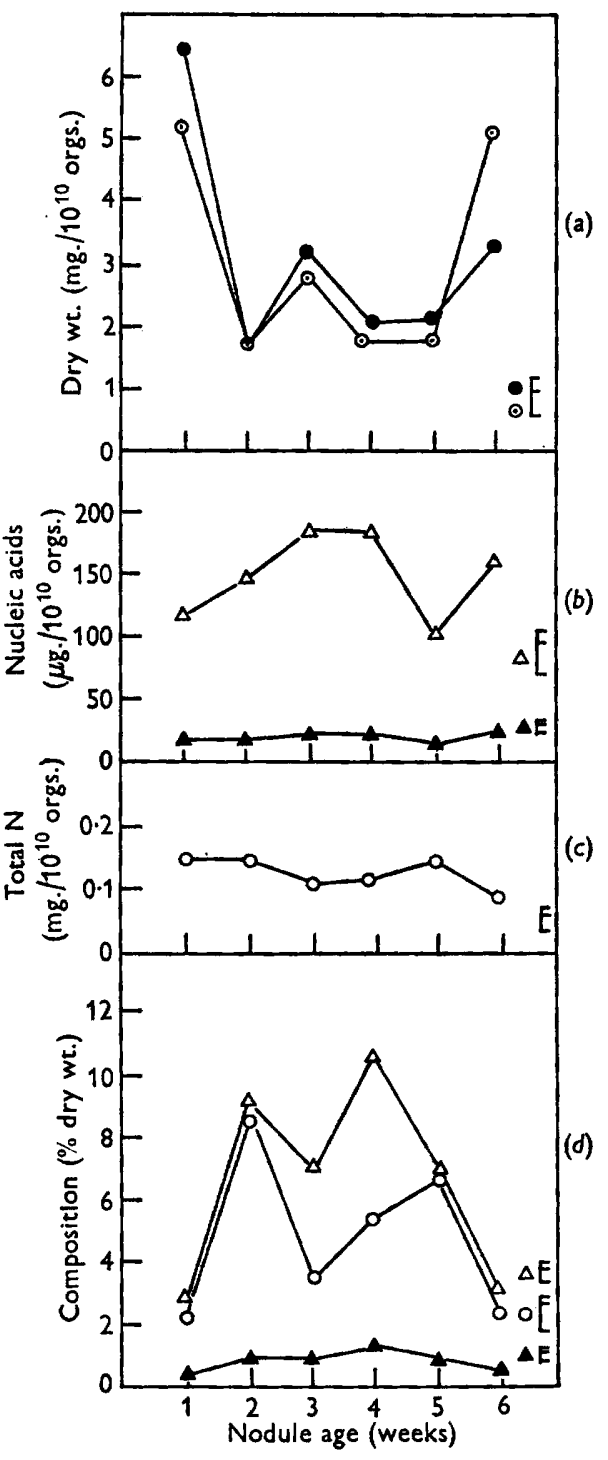

Fig. 4

Fig. 3. Changes in bacteroid respiration with age of nodules. Plants grown in: $(a)$ soil in summer; (b) N-free culture in winter; (c) soil in winter. $\Delta-\triangle=$ succinate; $0-0=$ fumarate; $\boldsymbol{\Delta}-\boldsymbol{\Delta}=$ citrate; $\odot-\odot=$ acetate and malate; $\odot-O=$ pyruvate; $\square-\square=$ endogenous.

Fig. 4. Changes in bacteroid composition with age of nodules. (a) Changes in organism dry weight : $\odot-\odot=$ plants grown in soil in winter; $-\odot=$ plants grown in N-free culture in winter. (b) Changes in organism nucleic acid; $\Delta-\Delta=N A ; \Delta-\Delta=N T$. (c) Changes in cell-N total: $\bigcirc-O$. (d) Changes in percentage composition: symbols as in $(b)$ and (c). Differences for significance between successive points are shown thus- $-1 \%$ : where these are of similar magnitude, only the greatest is shown. 
only slightly from those by the bacteria grown in vitro. The molar uptakes of oxygen for succinate throughout nodule life remained fairly constant (Table $1 b$ ). It therefore seems that there is little or no change in pathways of substrate oxidation as between bacterium and bacteroid.

\section{Respiration of bacteria grown in vitro}

Respiratory rates $\left(q_{\mathrm{O}_{2}}\right.$ cell) for cultures of various ages are illustrated in Fig. 5e which shows that respiration was highest during active growth (Fig. 5a).
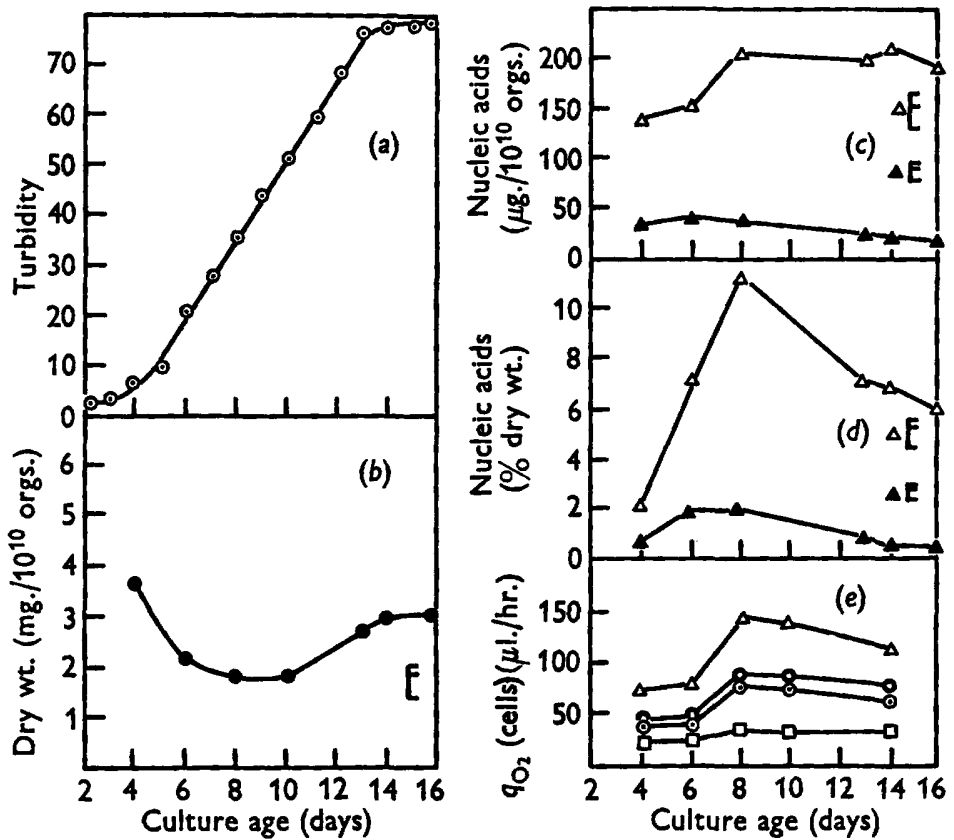

Fig. 5. Organism dry weight, nucleic acid content, and respiration of organisms from liquid culture at $20^{\circ},(a)$ growth as measured by turbidity; (b) organism dry weight; (c) organism nucleic acid, etc.: $\Delta-\Delta=\mathrm{NA} ; \Delta-\Delta=\mathrm{NT}$. $(d) \%(\mathrm{w} / \mathrm{w})$ nucleic acid: symbols as in (c). (e) Oxygen intake: $\Delta-\Delta=$ succinate; $0-0=$ fumarate; $\odot-\odot=$ malate; $\square-\square=$ endogenous. Differences for significance between successive points are shown thus- $-5 \%$ : where these are of similar magnitude only the greatest is shown.

\section{Changes in bacteroid constitution}

From the values for dry weight and bacterial count for suspensions from two experiments, the values of dry weight/10 10 organisms were calculated. Figure $4 a$ shows the patterns of change.

Changes in nucleic acid, acid-soluble nucleotide and total- $\mathbf{N}$ content for bacteroids from plants grown in soil are illustrated in Fig. $4 b$ and $c$. Figure $4 c$ shows that the changes in dry weight/10 10 organisms must be due to nonnitrogenous constituents since total- $N$ is almost constant. Nucleic acid would appear to play no part in the dry-weight changes from 1 to 2 weeks. 
The dry-weight increase at 2-3 weeks has a nucleic acid component as has the increase at 5-6 weeks, but these are only about $5 \%$ of the corresponding dry weight changes.

When nucleic acid, acid-soluble nucleotides and total- $\mathbf{N}$ are expressed as $\%$ dry wt. organisms it will be seen (Fig. $4 d$ ) that the pattern of change with time is almost a mirror image of the dry-weight pattern (Fig. 4a). This emphasizes that the magnitude of the dry-weight change is far greater than the change in any of the constituents examined.

Table 2. The ratio acid-soluble nucleotide: nucleic acid for bacteria from in vitro culture and bacteroids from nodules

Acid-soluble nucleotide (NT) was assayed by measurement of optical density at $260 \mathrm{~m} \mu$ of a $30 \%(w / v)$ trichloroacetic acid extract of the organisms made at $0^{\circ}$ for $30 \mathrm{~min}$. Nucleic acid (NA) was assayed by measurement of optical density at $268 \mathrm{~m} \mu$ of a pooled extract made by extracting organisms with $5 \%(w / v)$ trichloroacetic acid three times at $90^{\circ}$ for 10 min. In vitro cultured organisms were Rhizobium japonicum strain CC711 grown in yeast + mannitol broth at $20^{\circ}$. Bacteroids came from nodules of Lincoln soy bean plants grown in soil.

\begin{tabular}{|c|c|c|c|c|c|c|c|}
\hline \multirow{3}{*}{$\begin{array}{l}\text { Age of culture (days) } \\
\text { Ratio, NT:NA }\end{array}$} & & \multirow{3}{*}{\multicolumn{2}{|c|}{$\begin{array}{l}8 \\
0 \cdot 18\end{array}$}} & & \multirow{2}{*}{\multicolumn{2}{|c|}{14}} & \multirow[b]{2}{*}{16} \\
\hline & 6 & & & 13 & & & \\
\hline & $0 \cdot 27$ & & & $0-12$ & \multicolumn{2}{|c|}{$0 \cdot 10$} & 0.09 \\
\hline \multicolumn{8}{|c|}{ Bacteroids } \\
\hline $\begin{array}{l}\text { Nodule age (weeks) } \\
\text { Ratio, NT:NA }\end{array}$ & $\begin{array}{l}1 \\
0 \cdot 15\end{array}$ & $\begin{array}{l}2 \\
0 \cdot 12\end{array}$ & $\begin{array}{l}3 \\
0 \cdot 18\end{array}$ & $\begin{array}{l}4 \\
0 \cdot 13\end{array}$ & $\begin{array}{l}5 \\
0 \cdot 13\end{array}$ & $\begin{array}{l}6 \\
0 \cdot 18\end{array}$ & $\begin{array}{l}7 \\
0.25\end{array}$ \\
\hline
\end{tabular}

\section{Changes in the composition of bacteria from culture}

The growth at $20^{\circ}$ of the strain of Rhizobium used is illustrated by the turbidity/time curve of Fig. $5 a$, and the changes of dry weight and nucleic acid content/10 10 organisms at various stages of growth are shown in Fig. $5 b-d$. While nucleic acid (\% dry wt.) varied inversely with dry weight, the nucleic acid/organism remained constant at $200 \mu \mathrm{g} . / 10^{10}$ organisms during the most active stage of growth.

\section{DISCUSSION}

Patterns of change of respiration, cell dry weight, acid-soluble nucleotides and nucleic acid have been established for the developing bacterial component of soybean root nodules. In the experimental system used in this work there was a decrease in the respiratory activity of the bacteria isolated from the nodules before the beginning of nitrogen fixation, which began when the nodules were approximately 2 weeks old. From the microscopic observations this corresponds to the cessation of bacterial proliferation within the host cells, i.e. the beginning of the bacteroid condition. Further changes in respiratory rates of the bacteroids during the functional life of the nodules bore some relationship to changes in the rates of nitrogen fixation. When the weekly plant nitrogen increments from Fig. 2 are compared with the $q_{\mathrm{o}_{2}}$ of the bacteroids from the nodules on those plants (Fig. $3 b$ ) it will be seen that the increase in $\mathrm{N}$-increment from 2 to 3 weeks corresponds with an increase in respiration: the increments then remained fairly steady from 3 to 5 weeks when respiration changed only 
a little. The sharp increase in respiration which preceded nodule breakdown, however, occurred while the steady rate of nitrogen fixation was continuing. From this it seems that the changes in respiration which occur in the bacteroids are not always directly concerned with the nitrogen-fixing functions of the tissue. This contrasts with nitrogen fixation in Azotobacter where there is a close relationship between amount of substrate oxidized by the bacteria and amount of $\mathrm{N}_{2}$ fixed (Wilson \& Burris, 1943), and hence between respiratory rate and $\mathbf{N}_{2}$-fixation rate.

The general pattern of respiratory change of the bacteroids during the nodules' active life was reproduced on three occasions, although the limits within which the changes occurred in any one experiment seemed to be related to the size of the plants from which the nodules were harvested. The summer-grown plants were the largest (20-60 g. top fresh weight) with the highest $q_{\mathrm{O}_{2}}$ for the bacteroids, while with winter-grown plants, those grown in soil benefited from soil nitrogen and were larger (5-25 g. top fresh weight) and had higher $q_{\mathrm{o}_{2}}$ values for the bacteroids than those grown in $\mathrm{N}$-free culture (2-10 g. top fresh weight). The bacteroid respiration followed a similar pattern to changes in bacteroid dry weight. In contrast the cultured bacteria had the highest $q_{\mathrm{O}_{2}}$ values when they were growing most rapidly and when the organism dry weights was lowest. The failure of this strain of Rhizobium japonicum to completely oxidize substrates of the Krebs cycle suggests that this cycle may not operate in these organisms. If it is blocked there may be accumulation of one or more of the acids concerned in the preceding steps or these acids may be diverted to other processes. If the Krebs cycle does operate in these bacteria it would seem that the substrates supplied are oxidatively assimilated, a portion being completely oxidized to provide energy for the conversion of the remainder to lipid or carbohydrate reserve materials. These possibilities are at present being examined and will be the subject of a future communication.

Mitchell \& Moyle (1951) and Gale \& Folkes (1953) found that growth and protein synthesis in Staphylococcus were related to $\%(w / w)$ ribonucleic acid (RNA), growth being most rapid when this was at a maximum. They also concluded that RNA was synthesized from the acid-soluble nucleotides which attained maximum concentration before the RNA. In Rhizobium japonicum this relationship was also found to hold for growing cultures, $\%(w / w)$ nucleic acid (NA) being greatest during the logarithmic phase of growth, and acidsoluble nucleotide (NT) attaining its maximum concentration 2 days before nucleic acid reached its maximum. The work reported here has shown the desirability of relating $\%(w / w)$ nucleic acid to cellular nucleic acid content, since increases in the former value may be artefacts resulting from changes in organism dry weight and thus not mean that nucleic acid synthesis has occurred. The NT/NA ratio of 0.12 during the active growth of this strain of Rhizobium japonicum is comparable with the Mitchell \& Moyle (1951) value of 0.1 for the NT/(RNA + DNA) ratio of actively growing cells. In the bacteroids, however, both the NA content $/ 10^{10}$ organisms and the $\%$ NA content fell within the same limits as with growing cells at times during the experiment, although the NT values of the bacteroids were always lower than those of 
cultured bacteria. As has been shown, there was a change over from the proliferating bacterial form to the bacteroid form about 2 weeks after nodule appearance. During this period \%(w/w) NA increased to a value characteristic of actively proliferating cultures. This was largely due to a decrease in organism dry weight, NA/organism increasing only slightly. It seems unlikely therefore that the cessation of bacterial division within the nodule was caused by lowered nucleic acid content as suggested by Rautanen \& Saubert (1955). These authors found $2.98 \%(w / w) ~ N A$ in bacteroids from soybean nodules and $8.25 \%(w / w)$ in organisms grown in vitro but found smaller differences between bacteroids and organisms grown in vitro with cowpea nodule bacteria. Figs. $4 d$ and $5 d$ illustrate the danger of making these types of comparisons unless ages of nodule and culture are specified since both NA/organism cell and \% NA are dynamic quantities. Rautanen \& Saubert's (1955) figures, on the other hand, do not disagree with the figures presented in this paper when the culture was in early or late logarithmic phase and the nodules mainly 5-6 weeks old. It is more probable, however, that the figure of $2.98 \%(w / w)$ is an average for nodules of a variety of ages.

Although patterns of change with time of the various features examined in bacteroids differed, as one would expect, from the patterns of cultured bacteria, the general ranges of values obtained were similar in both types of cells. Other characteristics must therefore be examined in order to define differences between bacteroids and the organisms of Rhizobium cultivated in vitro.

The author wishes to record his thanks to Mr G. A. McIntyre for the analyses of significance and to Mrs M. Stiller for technical assistance.

\section{REFERENCES}

Allen, E. K. \& Allen, O. N. (1950). Biochemical and symbiotic properties of rhizobia. Bact. Rev. 14, 273.

Almon, L. (1933). Concerning the reproduction of bacteroids. Zbl. Bakt. 87, 289.

Bergersen, F. J. (1955). The cytology of bacteroids from root nodules of subterranean clover. J. gen. Microbiol. 13, 411.

Bergersen, F. J. (1957). The structure of ineffective root nodules of legumes: an unusual new type of ineffectiveness and an appraisal of present knowledge. Austr. J. biol. Sci. 10, 233.

Burris, R. H. \& Wirson, P. W. (1939). Respiratory enzyme systems in symbiotic nitrogen fixation. Cold Spr. Harb. Symp. quant. Biol. 7, 349.

Chen, H. K. \& Thonnton, H. G. (1940). The structure of 'ineffective nodules' and its effect on nitrogen fixation. Proc. roy. Soc. B, 129, 208.

Cheniae, G. M. \& Evans, H. J. (1956). Studies on nodule nitrate reductase. Plant Physiol. 31 (Proceedings supplement).

GaLe, E. F. \& Folkes, J. P. (1953). The assimilation of amino acids by bacteria. 14. Nucleic acid and protein synthesis in Staphylococcus aureus. Biochem. J. 53, 483.

McKNIGHT, T. (1949). Efficiency of isolates of Rhizobium in the cowpea group, with proposed additions to this group. Qd J. agric. Sci. 6, 61.

Matmaren, B. \& Hedín, C. (1947). Studies on the nucleotide metabolism of bacteria. Acta path. microbiol. scand. 24, 472. 
Mitchell, P. \& Moyue, J. (1951). Relationship between cell growth, surface properties and nucleic acid production in normal and penicillin treated Micrococcus pyogenes. J. gen. Microbiol. 5, 421.

Nutman, P. S. (1956). The influence of the legume in root nodule symbiosis. Biol. Rev. 31, 109.

Rautanen, N. \& SaUbert, S. (1955). Root nodules of leguminous plants; a chemical study. Suomen Kemist. $28 \mathrm{~B}, 66$.

Thorne, D. W. \& Burris, R. H. (1940). Respiratory enzyme systems in symbiotic nitrogen fixation. II. Respiration of Rhizobium from legume nodules and laboratory cultures. J. Bact. 39, 187.

Umbreit, W. W., Burris, R. H. \& Stauffer, J. F. (1945). Manometric Techniques and Related Methods for the Study of Tissue Metabolism. Minneapolis: Burgess Publishing Co.

Wilson, P. W. \& Burris, R. H. (1943). The action of inhibitors on hydrogenase in Azotobacter. J. gen. Physiol. 26, 277.

Wrlson, P. W. \& BURris, R. H. (1953). Biological nitrogen fixation-a reappraisal. Annu. Rev. Microbiol. 7, 415.

(Received 27 March 1958) 